\section{LA DOCENCIA ACTUAL DE LA ÉTICA EN LAS UNIVERSIDADES JESUITAS EN ESPAÑA}

\author{
Xabier Etxeberria \\ Universidad de Deusto \\ xetxemau@deusto.es
}

\section{THE CURRENT TEACHING OF ETHICS AT THE JESUIT UNIVERSITIES IN SPAIN}

Cómo citar este artículo/Citation: Etxeberria, X. (2016). La docencia actual de la ética en las universidades jesuitas en España. Arbor, 192 (782): a360. doi: http://dx.doi.org/10.3989/ arbor.2016.782n6005

Recibido: 04 noviembre 2014. Aceptado: 25 agosto 2015.

RESUMEN: En este artículo se presenta y analiza la docencia de la ética en los últimos 20 años en las universidades jesuitas en España. Se combina para ello el acercamiento histórico y sistemático. Respecto a este, se resalta la focalización de esa docencia en la ética de las profesiones, destacando todas sus implicaciones. Entre estas son importantes: la asunción de un enfoque de universalidad y pluralidad armonizado con la identidad jesuita de la universidad, la inclusión de la dimensión fundamental y cívica de la ética, el enraizamiento en los contextos sociales e históricos de las profesiones, la concepción compleja de la ética profesional pivotada en el bien interno de las profesiones. Se concluye proponiendo procesos de enseñanza-aprendizaje que reasuman todos estos supuestos y ofreciendo la experiencia al ámbito universitario como una de las referencias posibles para debatir el lugar de la ética en la Universidad.

PALABRAS CLAVE: Secularidad; pluralismo; profesión; ética de las profesiones; bien interno; docencia de la ética.
Copyright: (c) 2016 CSIC. Este es un artículo de acceso abierto distribuido bajo los términos de la licencia Creative Commons Attribution (CC BY) España 3.0.
ABSTRACT: This article presents and analyses the teaching of ethics at Jesuit universities in Spain over the last 20 years and achieves this by combining historical and systematic approaches. The systematic approach highlights the importance given to the teaching of the ethics of professions, emphasizing its main implications: the assumption of an understanding of universality and plurality congruent with the Jesuit identity of the university; inclusion of the fundamental and civic dimensions of ethics; the embedding of ethics within the social and historical contexts of the professions; the multifaceted conception of ethics based on the intrinsic goodness in each profession. It concludes by proposing teaching-learning strategies that incorporate the above-mentioned perspectives and offering the experience of Jesuit universities as a contribution to the debate on the position of ethics in universities.

KEYWORDS: Secularity; pluralism; profession; ethics of the professions; intrinsic goodness; teaching of ethics. 


\section{INTRODUCCIÓN}

El objetivo de este trabajo es dar cuenta reflexiva del lugar y modo de la docencia de la ética dirigida a todo el alumnado (descarto aquí, por tanto, la atención a la ética filosófica o la moral teológica en las facultades respectivas como parte de su currículo específico) en las universidades jesuitas en España en la actualidad. Debo advertir al respecto que no pretendo ofrecer una descripción detallada de la historia recorrida ni de los programas educativos existentes, aunque aparecerán datos significativos especialmente de la primera, ni tampoco hacer una evaluación de la práctica realizada, con sus logros y con sus carencias y contradicciones. Me centro más bien en la propuesta como tal. Por una razón interna a estas universidades: vale la pena dedicarse a repensarla, para darle más solidez. Y una razón externa, especialmente relevante por el lugar en el que este texto se publica: creo que la propuesta es suficientemente inspiradora como para ser considerada una referencia valiosa, con otras, en los debates universitarios en general -que, por tanto, desborden el ámbito jesuita y privado- en torno a un tema tan importante como el del lugar de la ética en las universidades.

Se impone además una segunda observación introductoria: ni tengo ni pretendo ninguna representación institucional sobre esta cuestión. Lo que supone que lo que diga estará arraigado en los procesos y debates que hemos tenido los que nos hemos ocupado del tema en UNIJES (la red de universidades jesuitas en España), será deudor de ellos, pero a su vez, estará sujeto a mis interpretaciones y desarrollos. Desde la consideración, además, de que dentro de esta red, aunque se comparten pautas comunes respecto a la docencia de la ética, ha habido y hay un significativo pluralismo, debido a la historia singular de cada entidad universitaria y a su reconocida autonomía.

\section{EL TRASFONDO DE UN CAMBIO CULTURAL}

La propuesta de enseñanza-aprendizaje de la ética que voy a considerar tiene como trasfondo explicativo y en parte fundamentador un cambio de perspectiva cultural dentro de la universidad jesuita: el que supone hacerse cargo de la secularidad y el pluralismo no como hechos sociales llamados incluso a ser combatidos, sino como valores, si se postulan de un cierto modo.

En la tradicional definición de estas universidades como católicas y jesuitas figuraba históricamente el rechazo a la secularidad y al pluralismo que van emergiendo a partir de la modernidad ilustrada; rechazo que se trataba de hacer plenamente efectivo en el interior de ellas. El adjetivo "católico-jesuita", que marcaba la identidad propia, reconfiguraba decisivamente -y de acuerdo con la ortodoxia estricta-, al menos de modo oficial, el sustantivo universidad en los temas de valores éticos y de sentido. Podría situarse en los años 70 el momento de crisis de esta visión, tanto por factores externos -empuje social fuerte de la visión secular, detectable en alumnos y profesores seglares-, como internos -cuestionamiento argumentado de sus supuestos dentro de la universidad-. Ello acarrea en los 80 , con variaciones entre los diversos Centros, un debilitamiento del enfoque precedente y una aceptación fáctica al interior de ellos de dimensiones importantes de secularidad y pluralidad. Pero habrá que esperar a los 90 para que vaya emergiendo un nuevo planteamiento argumentado en torno a tales dimensiones, a fin de encontrarles un lugar formal dentro de la propia universidad, que pueda armonizarse, aunque sea tensionalmente, con la identidad jesuita.

En España esta evolución estuvo marcada por una historia en la que el franquismo tuvo un papel relevante que no hay que ignorar. Pero la evolución como tal ha sido algo común, al menos en los contextos culturales occidentales, aunque con especificidades en modos y tiempos según los países. Por ejemplo, en la AJCU, red norteamericana de universidades jesuitas, se publicó un estudio (Appleyard y Gray, 2000) en el que se proponen tres modelos sucesivos por los que habrían pasado sus centros: el modelo "control", hasta comienzos de los 60, que buscaba generar egresados fieles a la fe cristiana y a la doctrina moral de la Iglesia prevaticana y recelosos del pluralismo; el modelo "profesión", hasta bien entrados los 80, en el que la identidad católica es desplazada a un departamento de pastoral -separación- y el trabajo común se centra en educar al buen profesional; y el modelo "misión", a partir de los 90 que, cuestionando la autorrelegación de las cuestiones de fe-sentido y valores-ética a un área periférica y al mero respeto a la conciencia individual, busca que la identidad jesuita impregne el conjunto de la universidad pero sin que eso suponga volver al modelo control.

Por mi parte, no ya en perspectiva histórico-descriptiva sino tipológico-propositiva, he planteado tres opciones posibles o modelos respecto a cuestiones de ética y sentido, ante los que las universidades privadas en general tendrían que posicionarse: el de confesionalidad omniabarcante, en el que no hay pluralismo interno aunque se respete desde la distancia el externo; el de laicidad, en el que se propugna oficial- 
mente la neutralidad e imparcialidad de la institución; el de confesionalidad inspiradora, en el que se articula complejamente la acogida del pluralismo interno con la asunción de la identidad propia -en nuestro caso, jesuita- de la universidad en cuanto tal. ${ }^{1}$ Como puede constatarse, este último modelo que aquí no puedo describir en detalle, pretende ofrecer un marco de comprensión y orientación al reto de la armonización antes indicado. Advierto que, como tal, ni es un modelo oficial en UNIJES, ni expresa una manera única de afrontar el reto en ella, pues hay variaciones significativas tanto en profesores como en responsables de los Centros. Pero creo que, en lo más básico de él y en la práctica, hay un acuerdo ampliamente compartido.

Pues bien, considero que la propuesta de docencia de la ética que presento se sitúa en los entornos de este tercer modelo. Se concreta del siguiente modo: la ética que se plantea obligatoriamente a todo el alumnado, del que se respeta empáticamente la pluralidad en cuestiones de moral y sentido, debe tener una fundamentación que se sostenga secularmente de modo asumible por todos, sin referencia, por tanto, a referentes religiosos trascendentes; y unos contenidos que, expresando propuestas normativas universalizables y por tanto con conocimiento riguroso de ellas exigible a todos, incluyan como valor el pluralismo éticamente legítimo respecto a ideales de vida buena. Esto se traduce en la práctica en la remisión a una ética cívica sustentada en los derechos humanos y a una ética profesional -en la que se ha hecho más énfasis en UNIJES, como se verá- que, incorporando la primera, tiene también las mismas conexiones con la secularidad y la pluralidad. Como tales, ambas pueden ser enseñadas por profesores creyentes y no creyentes.

Ahora bien -matiz importante para que no nos situemos en el modelo de laicidad-, esta ética cívica y profesional deberá remitirse a una secularidad abierta en todos a contemplar la posibilidad de razonabilidad argumentada de propuestas morales y de sentido, incluyendo entre ellas las espiritual y religiosamente sustentadas. A estas últimas, además, se les da espacio formal en materias optativas también regladas, ofrecidas a la libertad de los alumnos, y en iniciativas no regladas que expresan, manifiestamente, la identidad cristiano-jesuita. Sin que ello suponga, hay que añadir, que se diseñan intencionalmente espacios marginales a la vida universitaria. Primero, porque lo común y lo optativo están amparados por la misma lógica básica. Segundo, porque así como la secularidad propuesta no cierra per se a lo religioso, la fe cristiana que se sabe, para ser tal, necesariamente acogida en la libertad y expandida en el amor, no solo no bloquea el respeto al diferente, sino que aporta al creyente una potente razón añadida a la secular que todos comparten. ${ }^{2}$ Hay así, a la vez, en interacción tensional en sí fecunda aunque no fácil en la práctica, confesionalidad cristiano-jesuita inspiradora de todas las iniciativas de la universidad y respeto a la secularidad y la pluralidad de los no creyentes. Lo ideal es que esto se complete encontrando espacios específicos de diálogo en la universidad, a los que convocar a todos, para confrontar argumental e incluso testimonialmente, las diferencias.

\section{UN APUNTE HISTÓRICO}

El comienzo explícito de la propuesta que estoy presentando de docencia en la red de universidades jesuitas en España (Ilamada COCESU hasta 2004 en que pasa a denominarse UNIJES) debe situarse en enero de 1993. En esta fecha la Universidad de Comillas organiza en El Escorial, con fuerte apoyo institucional, un Simposio de Ética de las profesiones, al que son invitados a participar representantes de los otros Centro de COCESU. En él, además de la exposición y debate de las ponencias (Fernández y Hortal, 1994), se constata la necesidad de establecer convocatorias periódicas de representantes de los Centros para intercambiar experiencias, reflexionar juntos y avanzar en una cierta coordinación en la docencia de esta materia y en la promoción de iniciativas conjuntas.

Esto se plasma en la constitución formal, en enero de 1994, del "Grupo de ética de las profesiones" que, amparado por los responsables de COCESU y de sus Centros, se encarga de asumir esos objetivos. Arranca con criterios muy básicos: a) aunque se considera que la ética debe estar presente en el aprendizaje de todas la materias de cada carrera, se ve muy conveniente que haya una asignatura específica que incluya la ética profesional en todas ellas -hasta ese momento únicamente se impartía deontología jurídica, ética empresarial y poco más-, no solo por realismo, pues es difícil pensar que va a estar transversalmente presente en todas las disciplinas de las diversas carreras, sino también para mostrar que se trata de una disciplina que tiene su propia consistencia y autonomía, desde las que cabe interpelar a las demás y a la profesión como tal; b) dado el pluralismo del alumnado universitario y la pretensión de dirigirse a todos, el enfoque de esta materia debe ser el de la ética filosófica, lo que reclama que se resitúe el modo y lugar de la inspiración cristiana de la universidad -aunque este objetivo no se plantee dentro del Grupo-; c) en el diseño e implan- 
tación de la materia habrá que respetar los procesos propios de cada centro, en función de su historia y sus contextos. Para la puesta en marcha de todo esto se aprovecha el hecho de que, a partir de 1993, las universidades españolas tienen que ir reelaborando sus planes de estudios siguiendo las directrices generales y específicas que el Estado había formulado entre 1987 y 1992, que desarrollaban la ley de Reforma Universitaria, lo que facilitó la introducción de las éticas de las profesiones. ${ }^{3}$

El Grupo de ética de las profesiones ha pretendido ser algo más que el de los representantes de las universidades. En él se distinguen tres círculos: el primero está compuesto por esos representantes, con los objetivos de comunicación, estímulo y coordinación de iniciativas comunes; el segundo lo configuran todos los profesores que imparten ética profesional, para los que se impulsan iniciativas diversas que faciliten su tarea; el tercero, potencialmente, lo constituye el conjunto de profesores, para fomentar la dimensión transversal de la ética en todas las disciplinas. Dirigidas a los círculos segundo y tercero se realizan encuentros de formación y diálogo en cada Centro. Además, para los componentes del círculo segundo, se han promovido iniciativas a nivel de UNIJES, entre las que destacan: un amplio e intenso curso de formación de profesores de Ética profesional, en los inicios de la puesta en marcha de la propuesta; simposios y jornadas sobre temas diversos como, entre otros, ética de las profesiones jurídicas, ética empresarial, ética y turismo, crisis de la democracia; la elaboración de una colección de manuales de ética de las profesiones, editada por Desclée de Brouwer que, por supuesto, tiene vocación de difundirse en el conjunto de las universidades e incluso fuera de ellas. En ella se han publicado ya 14 volúmenes, que invito al lector a visualizar en la web de la editorial.

El horizonte que se contempla con esta opción docente queda muy bien plasmado en el primer rasgo de la identidad y misión de la red jesuita, formulado ya en su etapa como UNIJES: "Formar hombres y mujeres como profesionales competentes y ciudadanos responsables que pongan su saber y sus competencias al servicio de los demás" (www.unijes.net). En lo que sigue, me propongo desarrollar todo lo implicado en él, ya con enfoque sistemático más que histórico.

\section{ÉTICA FUNDAMENTAL, CÍVICA Y PROFESIONAL}

Lo que aglutina la propuesta de docencia de la ética en UNIJES, como he adelantado, aunque con variaciones entre los Centros al concretarla en ellos, es la ética profesional. Ahora bien, esta es tomada en su sentido más implicativo. En todo profesional, con su identidad correspondiente, late la condición de persona individual que, con sus relaciones intersubjetivas, persigue una vida realizada, y la de ciudadano llamado a empeñarse con los demás en la convivencia en justicia y el logro del bien público. Pero no se trata de tres dimensiones que deban contemplarse en yuxtaposición: el ideal de persona buena se logra cuando se imbrican las vivencias éticas de las tres, en interpelaciones y apoyos mutuos. Se parta de la que se parta, se trata de incluir a las otras dos, no artificial y voluntaristamente, sino como desarrollo interno de ella. Lo que la propuesta pretende es, precisamente, que, desde el foco de la profesión, se comprenda que esta, si es bien vivida, se enraíza y se expande en la vida cívica, a la vez que plenifica personalmente a quien la ejerce.

En la práctica docente, esto se traduce en ofrecer una materia que sintetice la ética cívica y profesional, como es llamada expresamente en algunos centros de UNIJES. El profesional tiene que ser un buen ciudadano más allá de su profesión, pero también serlo a través de esta, impregnándola de sentido cívico, abierto a no descuidar su horizonte personal de plenitud. Es esto lo que justifica que la materia tenga pretensión de obligatoriedad para todo el alumnado. El que la síntesis se realice a partir de la profesión, le tiende a dar una concreción y una motivación con fuerza pedagógica. En cuanto a los contenidos más propiamente cívicos, para precisarlos se muestran muy adecuadas las categorías de ética cívica que se nos impone, remitiendo a los derechos humanos en su interdependencia e indivisibilidad, y de éticas de plenitud, optativas, que acompañan los caminos personales libres hacia una vida lograda, con sus complejas relaciones llamadas a plantearse ajustadamente. Es a través de estas categorías como puede concretarse la dimensión cívica de toda profesión y el civismo que la desborda.

Pero hay todavía más inclusividades. La ética profesional es una expresión de la ética aplicada, la que remite, por definición, a la ética fundamental, llamada a ofrecer la consistencia argumental última de lo que se propone, el rigor básico de la materia. Tenemos así, con lógica deductiva, una ética fundamental, que sustenta e inspira las éticas aplicadas, entre las que, en sociedades como las nuestras, es clave la que se concreta en las profesiones. Pero cabe también contemplar el proceso inductivamente, en una especie de círculo virtuoso: ahora son las profesiones las que plantean retos e iluminaciones que aclaran lo que es la ética aplicada así como las conexiones que esta tie- 
ne que mantener con la ética fundamental. Un texto de Hortal, quien ha ejercido un liderazgo relevante en la propuesta que estoy analizando, desarrolla sugerentemente esta línea, al mostrar que, sin negar que el todo ilumine la parte, también es muy importante indagar cómo la luz que se desprende de la parte puede ayudar a ver mejor el todo. Así, nos dice, la ética aplicada, y en concreto la profesional, con sus objetivos prácticos, empuja a elaborar aspectos de la teoría ética que no aparecen desde la mera preocupación por las fundamentaciones universalistas, porque "solo en lo particular se hace presente lo universal, y los principios nunca se acaban de entender bien si no es después de haberlos ido pasando por los diferentes contextos" (Hortal, 2004, p. 187).

Cuando se quiere resaltar todo esto, que debe tener su proyección en las metodologías utilizadas en la docencia, a la materia se le llama "ética fundamental y profesional". Que esta cuestión es relevante en la propuesta de docencia que comento resulta manifiesto en el hecho de que en la colección de manuales UNIJES a la que me he referido antes, el primero de ellos, que se me encomendó redactar, se titula "Temas básicos de ética", esto es, expone la ética fundamental que conviene tener presente para las éticas de las diversas profesiones que se tratan en los otros volúmenes. A este respecto conviene advertir que cuando se hace referencia a esta ética fundamentadora de lo profesional, se propone que se tenga presente no únicamente su perspectiva estrictamente normativa o deontológica, sino también la teleológica, incluyendo su variable aretológica (Etxeberria, 2000 y 2004a). Ello es debido a que al afrontar lo que es la ética profesional es muy relevante el telos interno de cada profesión, con su dinamismo propio a la hora de configurar la normatividad, como se verá luego.

La inclusividad inserta en la ética profesional no es reclamada únicamente por el dinamismo interno de esta. También, y especialmente, lo es por la persona clave en el proceso de enseñanza-aprendizaje, el alumno. Es él como persona el que integra las dimensiones más subjetivas con las cívicas y las profesionales -en proyecto-. Se trata de invitarle, a través de un proceso pedagógico, a que las vivencie imbricadamente de modo ético, como realidad actual y como proyecto de vida. En este sentido, la docencia de la ética que se propugna en UNIJES no tiene una mera finalidad teórica -cognitiva-, tiene una finalidad práctica de realización de la vida moral, en el alumno y en el profesor que le acompaña. En esto seguimos a Aristóteles cuando nos recuerda que "investigamos no para saber qué es la virtud, sino para ser buenos, ya que de otro modo ningún beneficio sacaríamos de ella" (1988, p. 160).

\section{SOBRE LAS PROFESIONES}

La focalización -así entendida- en las profesiones de la "materia obligatoria" de ética para todo el alumnado que se ofrece en UNIJES, no se apoya únicamente en razones pedagógicas de concreción y motivación. Tiene que ver también con lo que las profesiones son y con el papel tan relevante que ocupan hoy en día, tanto subjetiva como socialmente. Es decir, hay razones cuantitativas y cualitativas para el centramiento en ellas. Cuantitativamente, se ha dicho con razón, que vivimos en una sociedad profesionalizada como nunca. Cualitativamente, lo que de por sí es y supone la profesión nos pone en contacto expreso con la ética. Desarrollo esto último.

Dentro del Grupo de Ética de las Profesiones, ha sido Augusto Hortal quien, apoyándose en estudios de sociólogos relevantes, más esfuerzo ha dedicado a definirlas. Son, nos dice en sus primeras aproximaciones, "un conjunto de actividades ocupacionales en las que de forma institucionalizada se presta un servicio específico a la sociedad por parte de un conjunto de personas específicamente preparadas y facultadas para ello, y que se dedican de forma estable a estas actividades obteniendo de ellas su medio de vida" (Hortal, 1994b, p. 15; ver también Hortal, 1993 y 2002). Posteriormente, inspirándose en Kasher (2005), añade nuevos matices. En la profesión: se dan conocimientos sistemáticos específicos y destrezas prácticas necesarias para actuar; que se asientan en un compromiso de mejora que, huyendo de la mera reiteración mecánica, sabe confrontarse con la novedad; que abocan a iniciativas que tienen como criterio de excelencia el bien interno de la práctica profesional correspondiente; práctica cuyo significado se capta plenamente cuando se percibe la contribución específica que ofrece al conjunto de las personas y la sociedad tomadas en su globalidad.

Como se puede ver, en esta definición descriptiva hay ya dimensiones latentemente éticas, teleológica y deontológicamente. Se concentran en el servicio específico que la profesión ofrece a la sociedad y que debe ser considerado su bien interno, al que tienen que estar subordinados conocimientos y destrezas. En la definición va implícita la tesis de que el profesional es tal cuando es buen profesional, por tener que orientar su iniciativa por este criterio de bien. Por decirlo con un ejemplo extremo, los médicos al 
servicio del holocausto nazi no solo no eran médicos moralmente buenos, no eran médicos aunque dominaran muy bien conocimientos y técnicas propios de la medicina. $Y$ yendo a ejemplos cotidianos: en igualdad de condiciones tecnocientíficas diagnostica mejor -sirve mejor al bien interno de curar, prevenir y aliviar la enfermedad- el médico con virtudes morales como la escucha, que se muestran así insertas en la práctica médica. No entro aquí en el debate que puede despertar esta tesis. Me limito a señalar que, incluso si no es defendida en su radicalidad, ${ }^{4}$ es manifiesto que ningún profesional puede ignorar que su actividad, en cuanto está al servicio de un objetivo, se encuentra inexorablemente abocada a situarse en un marco moral, lo quiera él o no. Con lo que se le impone el reto de rehuir tanto el enfoque separatista de la profesión, desde el que se defiende que sus normas tienen que extraerse exclusivamente de la racionalidad propia de ella, como el enfoque moralista que descuida la competencia tecnocientífica, presuponiendo que la suple la buena voluntad ética; es propio del (buen) profesional imbricar creativamente ambas perspectivas (Etxeberria, 2004a).

Estas categorías de práctica y bien interno de ella -que consideramos centrales para la ética profesional- han sido tomadas de Maclntyre. Por práctica entiende este pensador "cualquier forma coherente y compleja de actividad humana cooperativa, establecida socialmente, mediante la cual se realizan los bienes inherentes a la misma mientras se intenta lograr los modelos de excelencia que le son apropiados a esa forma de actividad" (Maclntyre, 1987, p. 233). Las prácticas son mucho más amplias que las profesiones, pero todas estas son prácticas. Sus bienes internos son los diversos tipos de servicios, específicos de cada profesión, que ofrecen a la comunidad. Con ocasión del ejercicio de la práctica el profesional puede lograr bienes externos a ella, como el dinero, el poder o la fama. Pero solo son legítimos si no se persiguen instrumentalizando o contradiciendo los bienes internos; si estos son subordinados a los externos se cae en la corrupción de la práctica, la profesional en nuestro caso. La excelencia de esta, en cambio, viene determinada por el logro del bien interno, que precisará, de todos modos, los conocimientos y destrezas correspondientes.

Con estas consideraciones hechas a la definición de profesión nos estamos adentrando, como se ve y por dinamismos internos, en la ética de ella. Pero de momento quiero mantenerme en un nivel de arranque descriptivo, aunque tenga derivaciones morales. Un elemento de facticidad en las profesiones que se nos impone es el de su contextualidad e historicidad. Son ineludiblemente una realidad social, cultural e históricamente marcada, que se expresa en su ethos. Porque es, en efecto, en la historia de una tradición, en constante transformación fruto de dinámicas internas y de relaciones externas, en donde se forjan. En ella se define en concreto: qué profesiones se configuran, en qué consiste la competencia profesional que se les supone (en saberes y destrezas), cómo se concretan los bienes y servicios que le demanda la sociedad y cómo son interpretados (hay de por medio intensos procesos hermenéuticos, por ejemplo, para definir qué es la salud que atiende el médico o la educación que ofrece el pedagogo), cómo se institucionalizan, etc. Aunque, por otro lado, si es cierto que los cambios sociales implican cambios profesionales, también puede suceder lo contrario, que sean las corporaciones profesionales monopolizando ciertos espacios de poder las que impulsen cambios, aunque resulte menos común.

Esta realidad empírica de las profesiones tiene un claro impacto en la ética profesional. Muestra, para empezar, que ellas nos colocan de lleno en las dinámicas de la construcción social, con la relevancia que esto supone para el bien común y la justicia. Privan de este modo a las propuestas éticas en general y a las profesionales en particular de toda pretensión de ahistoricidad y aculturalidad, sin que ello deba significar que se cae en el relativismo: los valores en juego se interpretan en el contexto, son estimulados por él, se encarnan en él abriéndose así a expresiones plurales, pero manteniendo su fuerza crítica e innovadora frente a él, esto es, no siendo mero contexto. La ética profesional entra en contacto con todo esto. Por eso, conocer la historia de cada profesión, al menos en sus grandes rasgos, es una vía muy adecuada para comprender mejor lo que éticamente se le debe reclamar hoy, a través de su ajustamiento crítico a su contexto y de las transformaciones que se precisen en su ethos.

El contexto social actual está causando cambios significativos en las profesiones en general, aparte de los que provoca en profesiones específicas, haciendo incluso que unas desaparezcan y otras emerjan. En plan genérico las transformaciones están ligadas en especial a dos fenómenos: el de su gran tecnologización y el de su fuerte corporativización e inserción en organizaciones privadas y públicas, compatible con dinámicas de gran flexibilización cuando son actividades profesionales realizadas virtualmente en internet (lo que, por cierto, puede exigir que se matice la definición que se dio de lo que es la profesión). No es este 
el lugar para analizar tales fenómenos. Simplemente lo es para destacar cómo ambos suponen retos muy relevantes para la ética de las profesiones. El segundo, por lo que tiene que ver con la problemática del corporativismo y de la contribución de las profesiones al bien común y la justicia en situaciones no tanto de responsabilidad individual cuanto de co-responsabilidad organizacional. El primero por lo que supone, por un lado, de aumento de las posibilidades y la eficiencia y eficacia de las profesiones y, por otro, de tentación de reconvertirlas en solo destrezas técnicas con lógica tecnológica (lo que tradicionalmente se ha considerado "oficios", solo que muy tecnologizados), debilitando así la atención creativa, prudencial y responsable al contexto y a los procesos, y enfatizando la atención a los medios, que son despegados de los fines éticos (Hortal, 1994a y 2004). De nuevo, la ética profesional, siempre atenta al contexto, debe hacerse cargo de rasgos como estos, para destacar lo positivo de ellos y afrontar críticamente sus derivas negativas.

Pues bien, la propuesta de docencia de la ética de los Centros de UNIJES focalizada en la ética de las profesiones, se propone en principio integrar todas estas implicaciones que acarrea la propia naturaleza de la profesión y que, como se ve, le dan una gran relevancia.

\section{LA ÉTICA DE LAS PROFESIONES}

Hemos visto cómo al definir las profesiones nos hemos adentrado con espontaneidad en el ámbito de la ética. Este se asume de modo más directo y pleno cuando nos proponemos expresamente hacer una ética de las profesiones. Si acudimos a la producción filosófica, percibimos que ha sido muy escasa la atención que le han prestado a ella los filósofos. Quizá con la excepción de la ética médica, pero en cuanto que se presenta como bioética, desbordando lo que es propiamente la profesión. La ética profesional la están construyendo en buena medida los propios profesionales, con ayuda de estudios de sociólogos. Un implícito de la propuesta docente que estoy presentando es que en esa construcción, sin olvidar a ambos colectivos, deben implicarse de modo más intenso los filósofos morales, interactuando con ellos.

Se enfoca fecunda y ampliamente la ética profesional cuando se consideran desde la perspectiva ética, en el marco de cada profesión, estas variables articuladas entre ellas: qué hay que hacer, quiénes, a quiénes, para qué (un para qué de tipo ignaciano, podría decirse en UNIJES, no de tipo utilitarista al uso). En conjunto, como puede verse, domina jerarquizadamente la perspectiva de la persona, frente a la de las acciones y su normatividad, importantes, pero con "subordinación imbricada", esto es, no meramente instrumental.

Para responder a esas variables en su complejidad, guiadas por la prevalencia de las personas implicadas en el acto profesional, se imponen dos referencias básicas: la de la dignidad y la del bien. O quizá, mejor, la del bien a y de quienes son sujetos de dignidad, de esa dignidad que merece no solo respeto sino apoyo. Entre quienes estamos alentando la docencia de la ética en UNIJES, los hay más aristotélicamente teleológicos o más kantiano-discursivamente deontológicos, pero la ética de las profesiones empuja siempre a dar relevancia a la ética de bienes. El para qué gracias al cual alguien ofrece un servicio a alguien (incluso siendo remunerado), el bien interno de la profesión, es referencia clave, como se está viendo. Hacer bien lo que se hace para hacer el bien a quien se hace está en el corazón de la actividad profesional, en la conciencia de que habrá siempre un contexto y una pluralidad al definirlo. Esta última puede pedir la correspondiente jerarquización entre bienes. Pero, siempre, con el aglutinante de una orientación finalista global que incorpora la dignidad como fundamentación y como criterio de control y que se expresa como aspiración -que la profesión ayuda a configurar- a una vida humana lograda y como tal feliz.

En la propuesta docente de UNIJES no se está haciendo especial mención a Ricoeur (aunque personalmente lo tengo en cuenta), pero pienso que su definición de la intención ética como: anhelo de vida realizada -desde la estima de sí, en autonomía-, con y para los otros -con dinámicas de respeto y solicitud-, en instituciones justas -alentadas por el sentido de la justicia y estructuradas según criterios de justicia-, da muy buenas pistas a las éticas profesionales para esa orientación teleológica llamada a articularse con lo deontológico (Ricoeur, 1996).

Está siendo común hacer esta articulación proponiendo para la ética general de las profesiones, con las adecuadas acomodaciones y generalizaciones, los principios de la bioética: beneficencia, autonomía y justicia, el primero netamente finalista, los otros deontológicos (el de no maleficencia adquiere mayor o menor relevancia según como sea concebido). Así sucede en la docencia en UNIJES, siendo esta la perspectiva que asume Hortal en su libro dentro de la colección mencionada, "Ética general de las profesiones" (Hortal, 2002). Es una perspectiva que se muestra fecunda. Ahora bien, como puede verse en este volumen, no hay que olvidar otras categorías clave 
como la responsabilidad, de algún modo transversal a los principios y muy apegada a los contextos y a las mediatizaciones de la actividad profesional (tecnológica, económica, organizativa, etc.). Y hay que estar atentos también a referentes finalistas y principios específicos de cada profesión. ${ }^{5}$

He destacado antes que en las éticas profesionales se imponía la prioridad del centramiento en las personas, en el bien de quienes son sujetos de dignidad. Pero esa prioridad nos pide algo más: que nos fijemos en la propia construcción moral del ser de las personas que intervienen en la relación profesional. Nos topamos aquí con las virtudes o excelencias personales, modos de ser que constituyen nuestro carácter moral, actualización de nuestras potencialidades de bien-ser (Aristóteles, 1988). Esto es especialmente relevante para el profesional, llamado a configurarse como persona constituida moralmente por las virtudes, con especial énfasis en las que, bien trabadas entre ellas, son más relevantes para su profesión, de modo tal que su actividad surja espontánea, constante y afinadamente de ellas. Y es también muy importante, en un número significativo de profesiones -como la educativa, que aquí nos interesa tanto-, para aquellas personas a las que se atiende, en forma de acompañamiento a su autoconstrucción como personas virtuosas y, como tal, con vida lograda y abierta al bien público. En UNIJES los énfasis en esta categoría a la hora de abordar la ética profesional son diversos, pero pienso que vale la pena abordar el reto de una mayor y más activa presencia de ella. Hortal (2006) tiene un estudio sugerente dedicado a ello. Por mi parte, destaco la perspectiva aretológica -ensamblada con la finalista y deontológica- en todos mis acercamientos a éticas profesionales específicas. Un ejemplo para la ética médica puede verse en Etxeberria (2004b). Propongo un planteamiento general sobre las virtudes y la educación en ellas, con el horizonte de la convivencia, en Etxeberria (2012). En definitiva, si los principios y la atención a las consecuencias piden que nos fijemos en las acciones, para decidirlas bien y para evaluarlas, las virtudes nos piden que nos fijemos en los agentes, en las personas en su construcción moral.

El centramiento en las personas nos focaliza en quién hace el bien y a quiénes. Pero no podemos ignorar el marco en el que están. Y este marco está siendo hoy, como adelanté, muy marcadamente el de las organizaciones, privadas, sociales y públicas. Ciertamente, para los profesionales que ofrecen sus servicios enmarcados en ellas, y a veces también para los clientes o usuarios que, aunque sean más domi- nantemente individuos, pueden ser también agrupaciones u organizaciones. Esto es, no debe olvidarse la relación intersubjetiva entre profesionales y usuarios a la hora de concretar la ética de las profesiones, pero no puede reducirse a ella, debe contemplar las organizaciones, debe incluir una ética de las organizaciones. Lozano (1999) subraya muy bien este dato al mostrarnos cómo la ética de empresa debe ser en su núcleo ética de las organizaciones. Este es un caso extremo entre las profesiones, pero a la vez ilustrativo.

Al abordar la ética de las profesiones no podemos ignorar los códigos deontológicos -con sus correspondientes comités de ética- que poseen todas las que son socialmente relevantes. Elaborados por los propios profesionales (son su autorregulación ética), definen su contribución específica a la sociedad y enfatizan el polo deontológico señalando los valores, principios y normas que deben regular sus acciones con los clientes, los otros profesionales, las instituciones, etc. Sabemos los riesgos que tienen de corporativismo pero no es menos cierto que pueden expresar muy bien la auto-corresponsabilidad de los profesionales. Y, publificados, son además una referencia con la que evaluarlos socialmente. En definitiva, son parte significativa de la ética de las profesiones, aunque cabe el riesgo reducirla a ellos. En la propuesta docente en UNIJES tratamos de reconocerles su lugar, pero en formas tales que no solo no oscurezcan los referentes más de fondo que aquí estoy resaltando, sino que los supongan y prolonguen. Además, intentando luchar contra la tendencia a su irrelevancia en la vida cotidiana de los profesionales.

\section{LA DOCENCIA DE LA ÉTICA DE LAS PROFESIONES}

Las consideraciones precedentes han ido mostrando cómo se concibe la ética de las profesiones en UNIJES, con variaciones internas en los Centros a partir de la perspectiva común, repito una vez más. Nos queda ya únicamente hacer referencia a la docencia de esa ética así enfocada.

Lo primero que conviene destacar es que se ve importante que el profesor de ética de las profesiones sea un "buen profesional", un buen educador. Por coherencia. Y porque ejercerá su labor mucho mejor. Él también tiene que orientar su práctica a partir del bien interno de la misma, de la interpretación del ducere como "guiar", en el sentido de ayudar a los estudiantes, en colaboración respetuosa con su autonomía, a caminar por la vía del aprendizaje ético; y del ex-ducere en el sentido de facilitarles que saquen lo mejor de ellos mismos en convicciones y virtudes. ${ }^{6}$ En el Grupo 
de Ética de las Profesiones se recuerda con frecuencia el dato de que "vocación" y "profesión" son originariamente términos religiosos que hacen referencia a llamada y compromiso público (que la "profesión de profesor" parece magnificar), considerándose que la autenticidad en la buena configuración de la identidad de uno mismo y de su fecundidad hacia el exterior, pasan por una buena acogida de ambos. Aunque estos significados han caído socialmente, no estaría mal recuperarlos con un enfoque secular generalizable, porque el fondo de ellos es valioso para todos. Lo es especialmente para profesiones como la de profesor-educador, y más aún si cabe en el ámbito de la ética. Si su tarea es para él mero medio para el logro de otros objetivos, si la coloca en la lógica mercantil, con toda probabilidad la deformará gravemente.

Este profesor vocacionado debe a su vez tener los conocimientos éticos y de la profesión, así como las destrezas pedagógicas que se precisan, para fomentar eficazmente el bien interno. Aquí nos encontramos con un problema. Porque quien imparte docencia en la materia de la ética profesional, por ejemplo, de la ingeniería, puede ser de arranque o experto en ética filósofo- o experto en el conocimiento de la profesión -ingeniero-. Augusto Hortal propuso la afortunada expresión de "bilingüismo asimétrico" para afrontar esta situación: el experto en ética tendrá que adquirir conocimientos básicos del mundo de la ingeniería para abordar bien su tarea, aunque siempre serán su segunda e imperfecta "lengua"; y el ingeniero, del mismo modo, tendrá que lograr conocimientos éticos básicos para la ética de la profesión. Lo ideal es que se constituya un equipo de profesores con ambos perfiles y amplia capacidad de diálogo y colaboración, para que asuma como tal la docencia de la ética, en este caso en la ingeniería.

Quien asume de este modo la docencia de la ética debe ser consciente, de todos modos, de que la educación universitaria en ella le desborda. En la propuesta en UNIJES se tiene muy claro que la excelencia de la enseñanza-aprendizaje de la ética solo se logra si la materia específica en la que se aborda es un buen catalizador de las conexiones con lo moral que se dan en el conjunto de disciplinas de cada carrera universitaria, así como en las dinámicas estructurales de la universidad (también la institución como tal tiene que remitirse a los criterios de justicia y de servicio). De lo primero se deja constancia al proponerse, como indiqué antes, un "tercer círculo" de profesores, los que no imparten docencia de la ética pero tienen que sentirse implicados en ella. Quien da Derecho proce- sal o marketing no puede presentar su materia en formas tales que quiebren principios éticos básicos -por ejemplo, sometiendo el uso que se propugna de los conocimientos de la materia y de sus técnicas a la estrategia pura y dura de ganar-. No solo aparecerá una incoherencia flagrante ante el alumnado sino que se fragilizará fuertemente lo que se proponga en la clase de ética. Dicho en positivo: lo que se defiende en esta tiene que armonizarse con lo que se hace y se dice en el resto de materias y, también, en las tareas de investigación. Lo cual precisa diálogos interdisciplinares y procesos formativos, centrados en las materias específicas cuando sea conveniente pero con disposición a desbloquear las fronteras rígidas entre materias y departamentos, a fin de coordinarse en vistas al servicio al alumnado y la sociedad. La transversalidad de la ética, la interdisciplinariedad en ella, se harán entonces manifiestas. La experiencia está mostrando que es una tarea, a la vez, necesaria y muy difícil.

Volviendo a la docencia de la materia de ética, el profesor debe proponerse que los alumnos se hagan cargo, reflexiva y críticamente, de la dimensión moral de la profesión que ejercerán, con el enlace con el civismo que se propuso. Que, además, aprendan a argumentar y debatir racionalmente las problemáticas que aparezcan, con ese nivel de rigor que dará a la materia "credibilidad" universitaria. Que, igualmente, sepan captar la "relación dialéctica" entre los saberes científicos de su especialidad y los saberes éticos, siendo conscientes de su lógicas diferentes. Además, desbordando el nivel meramente cognitivo, el profesor debe ayudar a que se despierte la "sensibilidad moral" de los alumnos, a que avancen en la "clarificación personal" respecto a las opciones vitales en las que enmarcarán su profesión (Hortal, 1994b; Etxeberria, 2009).

Señalados así los objetivos más generales, el profesor de ética tiene que plantearse asumirlos en un proceso docente en el que incorpora en lo posible todas las dimensiones que han ido apareciendo en torno a la ética de las profesiones, que recuerdo someramente y que ofrezco a la vez como síntesis del recorrido de este escrito. Tendrá que tratar de:

- $\quad$ Situarse en la perspectiva de la universalidad abierta y dialogante que integra ajustadamente el pluralismo.

- Asumir integralmente la condición del estudiante como persona-ciudadano-futuro profesional.

- Aportar y exigir el rigor académico propio del saber de la ética, en parte por la remisión a la fundamentación filosófica de lo que se plantea, en 
parte por la integración de disciplinas científicas en lo que corresponda.

- Tener presente la historia y tradiciones de la profesión y su papel en la sociedad, de las que podrán aprenderse importantes lecciones para la actualidad.

- Estar muy atento al contexto hodierno de la profesión, pues es en él en el que tienen que concretarse aplicadamente sus grandes referencias éticas.

- Dentro de este contexto actual, estar especialmente atento a las organizaciones privadas, sociales y públicas que amparan y condicionan marcadamente a los profesionales, incorporando en lo que corresponda -algo variable según las profesiones- una ética de las organizaciones. Sin olvidar, por supuesto, las relaciones intersubjetivas entre profesionales y usuarios.

- También dentro de este contexto, hacerse cargo de la tecnologización de la profesión, para aprovechar todo lo que aporta, pero también para inducir atención crítica hacia sus derivas negativas: la de centrarse en los medios diluyendo los fines; la de convertir la profesión en una técnica "mecánica", olvidando que sigue siendo un "arte" implicando una "hermenéutica", al que debe servir la técnica; la de diluir la responsabilidad, al ponerla solo en el uso de los medios.

- A la hora de definir los diversos referentes éticos, tratar de tener una perspectiva articuladora, tensionalmente afinada, en la que estén presentes los enfoques deontológico, consecuencialista y aretológico teniendo en el horizonte a la persona.

- Tratar de que lo que aliente esa articulación sea el lugar clave del bien interno de cada profesión, en torno al cual pivota de alguna manera todo. El bien interno de la profesión dirigido a una persona sujeto de dignidad.

Hay, además, una perspectiva de la docencia de la ética de las profesiones que en UNIJES se quiere resaltar especialmente, tratando de hacer de ella una "peculiaridad fundamental", por supuesto, sin pretender acaparamiento sino todo lo contrario, celebrando y apoyando que se expanda más allá de UNIJES: tener siempre presente, decisivamente, el horizonte de la justicia social. En parte, esto está implícito en la inclusión de la ética cívica, con tal de que esta se tome en plenitud, esto es, remitiendo a los derechos humanos en su interdependencia e indivisibilidad. Pero merece la pena decir algo específico sobre esta llamada a la justicia, porque la referencia al civismo no siempre la cubre suficientemente.

En la propuesta que estoy presentando esta apelación se expresa de diversas maneras (Hortal, 2008; Etxeberria y Rodríguez, 2009; Hortal y Etxeberria, 2011). Me limito a apuntar, a modo de ejemplo, algunas consideraciones que cabe ofrecer a los estudiantes en cuanto futuros profesionales: al abordar el bien interno de la profesión hay que destacar su función social realizadora de la justicia, no solo su aportación a los individuos; a partir de lo cual, los profesionales tienen que asumir su cuota de responsabilidad que les corresponde en la construcción del bien público; lo que pueden hacer no solo con su práctica profesional directa sino también de otros modos como divulgando en la sociedad los saberes profesionales que benefician a los ciudadanos, o estimulando la corresponsabilidad que les afecta por su pertenencia a organizaciones con impacto social, o implicándose en los debates públicos con temáticas que tienen que ver con la profesión, o afinando y renovando en el colectivo profesional la comprensión social del bien interno, etc.; sabiéndose en un marco amplio de agentes (el profesional, el cliente o usuario, los responsables de las instituciones públicas y no públicas) en el que tienen que estar atentos a ejercer adecuadamente su función y exigir a los otros la propia de ellos.

Esto último Hortal (2008) lo sintetiza señalando que los profesionales: no deben caer en el corporativismo, el que relega a usuarios y responsables creando un espacio segregado para ellos en el que se protegen y soslayando las necesidades sociales y de los clientes; no tienen que alagar a los usuarios cayendo en el moralismo que enuncia metas deseables pero descuidando los modos de alcanzarlas; no deben dejar el campo de iniciativa únicamente a los responsables, que nos conducirán a la arbitrariedad y el despotismo. Solo cuando interactúan los tres protagonistas haciendo valer sus perspectivas y articulándolas con las otras dos, estamos en condiciones de promover la dimensión pública y de justicia de la ética profesional.

Concluyo estas líneas con una breve consideración. Ya señalé que UNIJES en cuanto organización general formula su identidad y misión a través de un primer objetivo, que cité, en el que se integra muy bien la docencia de la ética aquí propuesta. Añade luego que para realizar esa misión en sus Centros tiene como referencia un modelo pedagógico (remitido privilegiadamente a Ledesma y Kolvenbach) que contempla cuatro 
dimensiones: utilitas, humanitas, iustitia y fides. La docencia de la ética aquí propuesta se sitúa espontánea y connaturalmente en la utilitas no entendida al modo duramente consecuencialista sino de servicio. Pero, además, tiene que ver claramente con la humanitas en la medida en que se centra en las personas; y con la iustitia, si, como acabo de indicar, hace de la justicia social la perspectiva clave (además, focalizándola especialmente en el marginado, el oprimido, el vulnerable). Las tres dimensiones pueden asumirse secularmente, como en la materia que he estado presentado. Respecto a la fides cabe decir que, desbordando los

\section{NOTAS}

[1] La propuesta se ha debatido en la Universidad de Deusto (Etxeberria, 2008), en el Tecnológico de Monterrey-México (Etxeberria y Rodríguez, 2009) y en cursos formativos para profesores de UNIJES (los Ilamados Loyola II) en los que he tratado de afinarla y desarrollarla.

[2] Las universidades jesuitas encuentran un apoyo a esto en los decretos 2 a 5 de la Congregación General 34 del año 1995 (Un proyecto para el siglo XXI (Selección de textos de la Congregación General 34 de la Compañía de Jesús)), en los que se propone como parte de la misión el diálogo interreligioso y el diálogo con las tradiciones culturales, entre las que está evidentemente la ilustrada. Incluyendo, hay que añadir, su versión agnóstica hoy dominante en una cultura europea en la que, en palabras de Gauchet (2003, p. 25),"se ha pasado de una dominación global y explícita de lo religioso a una situación que podríamos llamar de secundarización y privatización de lo religioso".

[3] Esta propuesta no estaba geográficamente aislada en España. En la Federación Internacional de Universidades Católicas (FIUC) y su sección europea (FUCE), ya en 1982 se mostró interés en alentar temas de ética en relación con las titulaciones que se impartían, en formar profesionales con sentido ético. Con esta sensibilidad y objetivos, la FUCE se abrió a todo tipo de univer-

\section{BIBLIOGRAFÍA}

Appleyard, J. A. y Gray, H. (2000). Tracking the Mission and Identity Question. Three Decades of Inquiry and Three Models of Interpretation. Conversations on Jesuit Higher Education, 18, pp. 4-15.

Aristóteles (1988). Ética nicomáquea. Madrid: Gredos.

Etxeberria, X. (2000). Teaching Professional Ethics. En VV. AA. Matter of Breath. Foundations for Professional Ethics. Leuven: Peeters, pp. 209-233.

Etxeberria, X. (2004a). Ética fundamental para la ética profesional. UC Maule. Revista Académica de la Universidad Católica del Maule, 30, pp. 41-48.

Etxeberria, X. (2004b). Virtudes éticas: una necesidad en cuidados paliativos. En Couceiro, A. (ed.). Ética en cuidados paliativos. Madrid: Triacastela, pp. 49-62.

Etxeberria, X. (2008). Misión, socialmente contextualizada, de la Universidad de Deusto. Mundaiz, 75, pp. 9-55. lugares de obligatoriedad y ofrecida a las dinámicas de libertad, puede inspirar y motivar al creyente a vivir las otras dimensiones, y a potenciar diálogos abiertos a todos con el criterio básico de respeto empático a la pluralidad. Creo que con estas referencias y todo lo dicho precedentemente, la propuesta aquí descrita expresa un modo de presencia de la ética en la universidad que vale la pena ofrecer, con otros, al debate interuniversitario en general, en la búsqueda compartida del lugar que la ética debe ocupar en nuestros Centros, con expresiones diversas según sus identidades y contextos, pero siempre relevante.

sidades, alentando una iniciativa que cuajó como Red Europea de Ética. COCESU-UNIJES, a través del Grupo de Ética de las Profesiones, ha estado presente en estos procesos, con más o menos protagonismo según los momentos. También hay que dejar constancia de las conexiones del Grupo con AUSJAL, red latinoamericana de universidades jesuitas.

[4] Por ponerlo también con un ejemplo que cabría debatir: el ingeniero que diseña puentes puede pensar que es profesional competente si los diseña bien y satisface así a su cliente, al margen de que la finalidad de ellos sea abrir el paso hacia una población para proporcionarle los alimentos que necesita para sobrevivir o a otra para exterminarla violentamente. Puede considerar que el "para qué" juzgado éticamente es algo añadido externamente a lo que define su profesión.

[5] Para la ética de la empresa, Lozano propone una sugerente articulación de la tradición deontológica, consecuencialista y aretológica sintetizándolas como hermenéutica de la responsabilidad (1999, pp. 25-34).

[6] Para ampliar la ética profesional de los profesores véase Martínez Navarro (2010). Analiza el bien interno de ella en el c. IV.

Etxeberria, X. y Rodríguez, D. E. (2009). La orientación ética de la Universidad. El caso del Tecnológico de Monterrey. Monterrey: Instituto Tecnológico y de Estudios Superiores de Monterrey.

Etxeberria, X. (2009). La perspectiva social de la ética de las profesiones. En Cañón, C. y Villar, A. (coords.). Ética pensada y compartida. Madrid: Universidad de Comillas, pp. 161-180.

Etxeberria, X. (2012). Ética para convivir. Madrid: PPC.

Fernández, J. L. y Hortal, A. (comps.) (1994). Ética de las profesiones. Madrid: Universidad de Comillas.

Gauchet, M. (2003). La religión en la democracia. Madrid: El Cobre.

Hortal, A. (1993). Ética de las profesiones. Diálogo filosófico, 26, pp. 205-222.

Hortal, A. (1994a). Ética y tecnificación de las profesiones. En Fernández, J. L. y Hortal, A. (comps.). Ética de las profesiones. Madrid: Universidad de Comillas, pp. 75-82. 
Hortal, A. (1994b). La ética profesional en el contexto universitario. Madrid: Universidad de Comillas.

Hortal, A. (2002). Ética general de las profesiones. Bilbao: Desclée.

Hortal, A. (2004). Estatuto de las éticas aplicadas y ética profesional: ¿qué puede aprender la ética de la ética de las profesiones? En Murillo, I. (coord.). Filosofía práctica y persona humana. Salamanca: Universidad Pontificia, pp. 183-198.

Hortal, A. (2006). Virtudes del profesional. En Silveira de Brito, J. H. (coord.). Ética das Profissões. Braga: Universidade Católica Portuguesa, pp. 33-51.

Hortal, A. (2008). La dimensión pública de la ética de las profesiones. En Reimao, C. (coord.). Desafíos da Modernidade. Lisboa: Universidade Lusíada, pp. 17-30.

Hortal, A. y Etxeberria, X. (eds.) (2011). Profesionales y vida pública. Bilbao: Desclée.

Kasher, A. (2005). Professional Ethics and Collective Professional Autonomy: A Conceptual Analysis. Ethical Perspectives. Journal of the European Ethics Network, 11, 1, pp. 67-98. https://doi. org/10.2143/EP.12.1.583363
Lozano, J. M. (1999). Ética y empresa. Madrid: Trotta.

Martínez Navarro, E. (2010). Ética profesional de los profesores. Bilbao: Desclée.

MacIntyre, A. (1987). Tras la virtud. Barcelona: Crítica.

Ricoeur, P. (1996). Sí mismo como otro. Madrid: Siglo XXI.

\section{Recursos de Internet}

Un proyecto para el siglo XXI (Selección de textos de la Congregación General 34 de la Compañía de Jesús) [En línea]. Disponible en http://www.google.es/url?sa=t\&rct=j\&q=\&esrc=s\&source= web\&cd=1\&ved=0ahUKEwjCx6bm2e7RAhWFOBQKHdkPDtkQF gggMAA\&url=http\%3A\%2F\%2Fwww.mercaba.org\%2FSANLUIS \%2FEspiritualidad\%2FSJ.Congr.Gen.34.Selecci\%25C3\%25B3n.rtf \&usg=AFQjCNFO5MeiUa107TOOU2ECU5N95YpU6A 